\title{
ARTIGO \\ Biopolítica e o paradigma imunitário de Roberto Esposito
}

Ana Paula Sabetzki Boeing ${ }^{1}$

Como citar este artigo: SABETZKI BOEING, Ana Paula. Biopolítica e o paradigma imunitário de Roberto Esposito. Revista de Ciências do Estado. Belo Horizonte: v. 5, n. 1, e14832. ISSN: 2525-8036.

Resumo: o objetivo deste artigo consiste em analisar o paradigma imunitário desenvolvido por Roberto Esposito no âmbito da biopolítica. A pesquisa é qualitativa e utiliza documentação indireta consistente em doutrina bibliográfica. As conclusões apontam que a noção de imunidade em Esposito está estruturalmente conectada com a modernidade, tem uma implicação negativa com a comunidade e um sentido de conexão entre vida e poder, mas pode destruir a própria vida se levada ao extremo. Além disso, a imunidade influencia as categorias jurídico-políticas tradicionais da soberania, liberdade e propriedade.

Palavras-chave: biopolítica; Roberto Esposito; imunidade; comunidade.

Recebido em 27.07.2019

Aprovado em 08.05.2020

Publicado em 24.06.2020

\section{INTRODUÇÃO}

Nos últimos anos o interesse da filosofia política foi atraído pelo conceito de biopolítica, que captou uma transformação da forma pela qual a política é entendida e teorizada (CAMPBELL, 2017, p. 13). Fenômenos como a gestão da natalidade, das endemias ou mesmo a prática terrorista e a imigração de massa não são suficientemente explicados dentro do paradigma da soberania.

Foi o sueco Rudolph Kjellen o primeiro a adotar o termo "biopolítica". Michel Foucault repropôs e requalificou o conceito, o que alterou de forma profunda a filosofia política (ESPOSITO, 2010, p. 33 e 45). A teoria de Foucault é a base sobre a qual Roberto

\footnotetext{
${ }^{1}$ Mestre em Direito do Estado pela Universidade Federal do Paraná. Especialista em Direito Constitucional. Procuradora do Estado do Paraná. E-mail: ana_boeing@hotmail.com. Orcid: https://orcid.org/0000-0002-90374254.
} 
Esposito - e outros autores como Giorgio Agamben, Gilles Deleuze, Michael Hart e Antônio Negri - construíram as suas análises biopolítica (CAMPBELL, 2017, p. 31).

Esposito desenvolveu o paradigma imunitário e, com ele, contribuiu de forma verdadeiramente original e importante ao aprofundamento do debate. Timothy Campbell (2017, p. 14) afirma que o seu pensamento constitui "uma das mais potentes lentes disponíveis para observar como a vida continua a ser tomada - e frequentemente aniquilada pela política" e "uma brilhante tentativa de abrir um horizonte de uma possível biopolítica afirmativa, escapando assim de uma concepção totalmente negativa dos processos em andamento".

Nesse contexto, este artigo pretende analisar o paradigma imunitário de Roberto Esposito. O estudo partirá das noções desenvolvidas por Michel Foucault sobre poder disciplinar e biopoder. Após será analisada a noção de imunidade, que foi introduzida de forma original no debate biopolítico pelo filósofo italiano. A imunidade será estudada: a) em seu sentido de conexão entre vida e poder e de autoconservação da vida; b) em sua implicação negativa com a comunidade; c) em sua conexão estrutural com a modernidade; d) em sua influência sobre as categorias jurídico-políticas tradicionais da soberania, liberdade e propriedade; e) em sua potencialização ao extremo.

\section{PARA ALÉM DO PODER SOBERANO: A POLÍTICA DE DISCIPLINAR OS INDIVÍDUOS}

Michel Foucault distingue duas espécies de poder: o soberano (ou jurídico) e o normalizador. O primeiro é aquele que se encarna na figura do Estado soberano e se origina da noção hobbesiana do pacto por meio do qual os indivíduos consentem em abrir mão dos poderes privados que possuíam no estado de natureza. Já o poder normalizador pode atuar sobre individualidades corpóreas (poder disciplinar) ou sobre populações (biopolítica), em ambos os casos com o objetivo de adequação a uma norma, a um padrão (FONSECA, 2012, p. 141-144).

Foucault (2005, p. 41-42) aponta quatro papeis que, historicamente, a teoria da soberania desempenhou. Inicialmente ela se referiu à monarquia feudal, como mecanismo de poder efetivo. Em um segundo momento, ela consistiu em instrumento e justificativa para a constituição das grandes monarquias absolutistas. A partir do século XVI e principalmente do século XVII, no contexto das guerras de religião, a teoria da soberania foi o grande instrumento da luta política. Ela foi utilizada por católicos e protestantes, aristocratas e parlamentares, realeza e senhores feudais, tanto com o sentido de limitar como para fortalecer 
o poder régio. No século XVIII, ela passou a desempenhar a função de elaboração do modelo das democracias parlamentares, como alternativa às monarquias absolutistas.

Porém a mecânica de poder da soberania era ineficaz para regular política e economicamente uma sociedade que passava por uma explosão demográfica e pela industrialização (FOUCAULT, 2005, p. 297-298). Nos séculos XVII e XVIII surgiu então o poder disciplinar, um novo mecanismo que tem procedimentos e instrumentos próprios. Tratou-se, para Foucault, de uma das grandes invenções da sociedade burguesa e instrumento fundamental para a implantação do capitalismo industrial (FOUCAULT, 2005, p. 42-43).

O poder disciplinar é empregado em instituições como a escola, o hospital, o quartel, a oficina, a prisão, a fábrica. Ele incide sobre os corpos individuais e permite deles extrair tempo e trabalho, em contraposição ao poder soberano, que atua sobre a terra e apropria bens e riquezas. Ele não é exercido de forma descontínua por tributos e outras obrigações, mas continuamente por vigilância. $\mathrm{O}$ seu pressuposto é uma trama de coerções materiais e não propriamente a existência de um soberano. O poder disciplinar se relaciona a procedimentos de distribuição espacial dos corpos (separação, alinhamento, vigilância) e organização de um campo de visibilidade em torno deles. São também utilizadas técnicas de aumento da força útil desses corpos, como exercícios e treinamento. Enquanto na teoria da soberania o poder absoluto se fundamenta no dispêndio absoluto do poder, nesse novo mecanismo o poder é calculado com o mínimo de dispêndio e o máximo de eficácia (FOUCAULT, 2005, p. 42, 288, 298).

O poder disciplinar tem um discurso próprio, que não se confunde com aquele empregado no campo jurídico. É o que afirma Foucault (2005, p. 45):

\footnotetext{
O discurso da disciplina é alheio ao da lei; é alheio ao da regra como efeito da vontade soberana. Portanto, as disciplinas vão trazer um discurso que será o da regra; não o da regra jurídica derivada da soberania, mas o da regra natural, isto é, da norma. Elas definirão um código que será aquele, não da lei, mas da normalização, e elas se referirão necessariamente a um horizonte teórico que não será o edifício do direito, mas o campo das ciências humanas. E sua jurisprudência, para essas disciplinas, será a de um saber clínico.
}

O poder disciplinar é, portanto, injustificável em termos da teoria da soberania e dela totalmente dessemelhante. Apesar dessa heterogeneidade, a teoria da soberania continuou a existir como ideologia do direito e, no século XIX, organizou os códigos jurídicos europeus elaborados a partir do Código de Napoleão. Para Foucault (2005, p. 44), dois motivos fazem com que a teoria da soberania não tenha desaparecido. É que, por um lado, ela foi, durante os séculos XVIII e XIX, um instrumento da crítica à monarquia e aos obstáculos à sociedade 
disciplinar. Por outro lado, a organização de um código jurídico centrado na noção de soberania permitia mascarar as técnicas de dominação do poder disciplinar.

Assim, Foucault (2005, p. 45) afirma que o poder se exerce nas sociedades modernas entre esses dois limites: um direito da soberania e uma mecânica da disciplina. Ambos são, porém, tão heterogêneos que "nunca se pode fazer que um coincida com o outro".

3 UM PASSO MAIS Adiante: A POLÍtica de GERIR A POPUlaÇÃo NO SEU ASPECTO BIOLÓGICO

Conforme exposto no tópico anterior, nos séculos XVII e XVIII surgiram as tecnologias disciplinares do trabalho, centradas no corpo individual. Já no século XIX emergiu uma nova tecnologia direcionada não ao homem-corpo (indivíduo), mas ao homem vivo ou homem-espécie (população) e que é típica do que Foucault denomina "sociedade de segurança" (FOUCAULT, 2008). Enquanto a disciplina vigia, treina, utiliza e eventualmente pune os corpos individuais, a nova tecnologia da segurança se volta à massa global dos homens que é afetada por processos próprios da vida, como o nascimento, a morte, a doença, a produção. Trata-se do que Foucault denomina "biopolítica" da espécie humana. As técnicas biopolíticas, também chamadas de mecanismos de segurança, não excluem as disciplinares, mas as integram, modificam e de certo modo as utilizam (FOUCAULT, 2008; 2005, p. 288289).

O biopoder emprega as previsões, estimativas, medições estatísticas, objetivando, por exemplo, baixar a morbidade, estimular a natalidade, aumentar a expectativa de vida. As doenças são encaradas não mais ao nível das epidemias - dramas temporários de morte iminente para todos -, mas das endemias - que são causadas por fatores permanentes relacionados à população, como a diminuição do tempo de trabalho, a baixa de energias e os custos econômicos. A medicina passa a focalizar a higiene pública, com instrumentos de coordenação dos tratamentos, centralização da informação e normalização do saber. Outro problema sobre o qual a biopolítica intervém é o da velhice, que é enfrentado não mais apenas com instituições de assistência, mas com mecanismos mais racionais como os seguros, seguridade, poupança individual e coletiva (FOUCAULT, 2005, p. 290-291).

A biopolítica lida, assim, com a população enquanto problema científico, político, biológico e de poder. A população surge como elemento novo para a teoria do direito, que só conhecia o indivíduo contratante e o corpo social que se constituía pelo pacto voluntário, e para as práticas disciplinares, que atuavam sobre o corpo individual. Por outro lado, a biopolítica se direciona aos fenômenos aleatórios que atingem a massa da população em um 
limite de tempo relativamente longo. São acontecimentos de série, que só se tornam pertinentes no plano coletivo (FOUCAULT, 2005, p. 292-293). Ela se relaciona, portanto, ao estabelecimento de mecanismos reguladores que objetivam estabelecer um equilíbrio no campo aleatório que é inerente à população (FOUCAULT, 2005, p. 293-294).

A teoria clássica da soberania tinha como um dos seus atributos fundamentais o direito de vida ou morte: o soberano podia fazer morrer ou deixar viver. A sua essência consistia no direito de morte, pois o soberano exercia o direito sobre a vida justamente porque poderia matar. Já a biopolítica se relaciona a um direito novo: o direito de fazer viver ou deixar morrer. Esse novo direito de soberania não elimina aquele antigo, mas o completa (FOUCAULT, 2005, p. 286-287). Para Foucault (2005, p. 285-286), um dos fenômenos fundamentais do século XIX foi essa "assunção da vida pelo poder" ou "uma tomada de poder sobre o homem enquanto ser vivo, uma espécie de estatização do biológico".

A norma, que pode se aplicar tanto ao corpo como à população, é o elemento que circula entre a disciplina e a segurança. Nesse sentido Foucault (2005, p. 302) fala em "sociedade da normalização", na qual o poder tomou conta da vida, dirigindo-se do corpo à população mediante o uso tanto das tecnologias disciplinares como dos dispositivos biopolíticos.

Conforme observa Ricardo Marcelo Fonseca (2002, p. 128-130), Foucault abriu um campo de análise que traz uma nova dimensão à questão do poder e permite ler o Direito como uma instância atravessada pela norma. Num contexto em que o discurso jurídico costuma analisar as relações de poder apenas em termos da soberania, evidencia-se um abismo entre o sujeito de direito, formalmente teorizado pelo legado iluminista, e o sujeito real, que experimenta na prática inúmeras formas de controle e sujeição por meio da norma (FONSECA, 2004, p. 280). Além disso, as contribuições de Foucault possibilitam repensar o denominado estado liberal do século XIX e a sua dita característica não intervencionista (FONSECA, 2012, p. 147-148):

[...] as formas de governamentalidade e de gestão de populações está muito além de um Estado abstenteísta e que só se concentra nos indivíduos. A lei, por outro lado, deixa de se mostrar como instrumento único e exclusivo da gestão política: as mais diversas formas de regulamentação (típicas dos mecanismos de segurança), que são muitas vezes infralegais e outras vezes até mesmo estão à margem do sistema clássico de fontes do direito, cumprem e cumpriram uma função central nas formas de gestão da vida a partir do final do século XVIII. A ideia pura de um "Estado legislativo" na chamada "era liberal", assim, parece se esfumaçar um pouco diante das inúmeras formas de governamentalidade emergentes nos saberes e práticas normalizadoras do período. 


\title{
4 O PARADOXO FOUCAULTIANO E A CHAVE INTERPRETATIVA QUE
}

\section{LHE FALTAVA}

Conforme exposto no tópico anterior, em Foucault a biopolítica promove a gestão da vida em seu aspecto biológico e objetiva essencialmente conservá-la ("fazer viver"). O filósofo, porém, afirma que o exercício do biopoder, no limite, poder ser utilizado para eliminar a vida. No século XX surgem os paradoxos (FOUCAULT, 2005, p. 303):

\begin{abstract}
Paradoxos que aparecem de um lado com o poder atômico, que não é meramente o poder de matar, segundo os direitos que são concedidos a todo soberano, milhões e centenas de milhões de homens (afinal de contas, isso é tradicional). Mas o que faz que o poder atômico seja, para o funcionamento do poder político atual, uma espécie de paradoxo difícil de contornar, se não totalmente incontornável, é que, no poder de fabricar e de utilizar a bomba atômica, temos a entrada em cena de um poder de soberania que mata mas, igualmente, de um poder que é o de matar a própria vida. De sorte que, nesse poder atômico, o poder que se exerce, se exerce de tal forma que é capaz de suprimir a vida. E de suprimir-se, em consequência, como poder de assegurar a vida. Ou ele é soberano, e utiliza a bomba atômica, mas por isso não pode ser poder, biopoder, poder de assegurar a vida, como ele o é desde o século XIX. Ou, noutro limite, vocês têm o excesso, ao contrário, não mais do direito soberano sobre o biopoder, mas o excesso do biopoder sobre o direito soberano. Esse excesso do biopoder aparece quando a possibilidade é técnica e politicamente dada ao homem, não só de organizar a vida, mas de fazer a vida proliferar, de fabricar algo vivo, de fabricar algo monstruoso, de fabricar - no limite - vírus incontroláveis e universalmente destruidores. Extensão formidável do biopoder que, em contraste com o que eu dizia agora há pouco sobre o poder atômico, vai ultrapassar toda a soberania humana.
\end{abstract}

Os paradoxos, segundo Foucault, se relacionam ao racismo, que foi inserido nos mecanismos estatais pelo biopoder. $\mathrm{O}$ racismo promove um corte biológico entre a raça que deve viver e aquela que deve morrer. Nessa perspectiva, a morte da raça inferior fortalece a raça superior e deixa a vida em geral mais pura e sadia (FOUCAULT, 2005, p. 304-306). O desenvolvimento do racismo nas sociedades modernas pode ser observado nas colonizações, nas guerras, no nazismo. Para Foucault, a especificidade do racismo moderno diz respeito não a ideologias ou mentalidades, mas às tecnologias do poder: o Estado utiliza a eliminação ou purificação das raças para que seja possível o exercício do seu poder soberano. Se o poder normalizador quer exercer o "velho direito soberano de matar", ele deve passar pelo racismo (FOUCAULT, 2005, p. 307-309).

Nesse contexto, Roberto Esposito (2010, p. 64-67) afirma que a explicação conferida por Foucault àqueles paradoxos é insuficiente:

Como se explica que no cume da política da vida se tenha gerado um poder mortífero tendente a contradizer o seu impulso produtivo? É este o paradoxo, o inultrapassável obstáculo, que não só o totalitarismo do século XX mas também o subsequente poder nuclear põem ao filosofo com vista a uma declinação resolutamente afirmativa da biopolítica: como é possível que um poder da vida se exerça contra a própria vida? [...] Se se considera o Estado nazi, pode dizer-se indiferentemente, como faz justamente Foucault, que tenha sido o velho poder soberano a adotar em seu favor o racismo biológico inicialmente nascido contra ele; 
ou, ao contrário, que é o novo poder biopolítico que se serve do direito soberano de morte para dar vida ao racismo do Estado. Ora bem, se se recorre ao primeiro modelo interpretativo, a biopolítica torna-se uma articulação interna da soberania; se se privilegia o segundo, a soberania fica reduzida a uma máscara formal da biopolítica. A antinomia emerge ainda com mais força no que se refere ao equilíbrio atômico. Deve-se olhá-lo do lado da vida, que, apesar de tudo, conseguiu preservar, ou da morte total que cessou de ameaçar?

Esposito (2010, p. 68-70) identifica na relação entre soberania, biopolítica e totalitarismo o ponto de máxima tensão e de potencial fratura interna do discurso do filósofo francês. Em Foucault totalitarismo e modernidade seriam ao mesmo tempo contínuos e descontínuos, inassimiláveis e inseparáveis. Para Esposito é evidente a razão dessa contradição. Se prevalecesse a hipótese continuísta (indistinção entre soberania, biopolítica e totalitarismo), ele seria obrigado a assumir o genocídio como paradigma constitutivo ou resultado inevitável da parábola da modernidade. Isso contrastaria com o seu sentido das distinções históricas. Por outro lado, se prevalecesse a hipótese descontinuísta, a sua concepção de biopolítica seria invalidada cada vez que a morte se projetasse no círculo da vida (ESPOSITO, 2010, p. 70):

Se o totalitarismo fosse o resultado daquilo que o precede, o poder teria desde sempre apertado a vida num amplexo inexorável. Se fosse a sua deformação temporária e contingente, significaria que a vida é eventualmente capaz de vencer qualquer poder que queira violentá-la. No primeiro caso, a biopolítica resolver-se-ia num poder absoluto sobre a vida, no segundo, num poder absoluto da vida. Apanhado entre estas duas hipóteses contrapostas, bloqueado na aporia que se verifica no cruzamento entre elas, o autor continua a percorrer ao mesmo tempo ambas as direções. Não corta o nó, com o resultado de não levar até ao fim as suas geniais intuições sobre o nexo entre política e vida. A dificuldade, a indecisão, de Foucault vai evidentemente muito além de uma simples questão de periodização histórica ou da articulação genealógica entre os dois paradigmas de soberania e biopolítica, para acometer a própria configuração, logica e semântica, deste último conceito.

Para Esposito, há um bloqueio hermenêutico em Foucault que parece estar relacionado à circunstância de que os termos da vida e da política são pensados como originariamente distintos e só posteriormente ligados entre si, de forma ainda extrínseca. Por essa razão eles permaneceriam indefinidos no seu perfil e na sua qualificação: Foucault não teria elaborado suficientemente os conceitos de política e de vida. Para o filósofo italiano, a biopolítica parece pedir uma diferente chave interpretativa, um novo horizonte de sentido que una essas duas polaridades num nexo mais estreito e complexo (ESPOSITO, 2010, p. 70-71). Foi no paradigma da imunização que Esposito (2010, p. 73) afirma ter encontrado "a chave interpretativa que parece escapar a Foucault”. 


\section{VIDA E PODER COMO PARTE DE UM ÚNICO E INDIVISÍVEL CONJUNTO: O PARADIGMA IMUNITÁRIO DE ROBERTO ESPOSITO}

O paradigma da imunização, para Esposito, preenche o vazio semântico existente em Foucault entre os polos que constituem o conceito de biopolítica. Vida e política, nessa perspectiva, são os dois componentes de um único e indivisível conjunto, que só adquire sentido a partir da relação entre eles. A imunidade não apenas promove a ligação ente vida e poder, mas é o poder de conservação da vida (ESPOSITO, 2010, p. 73-74).

Em uma perspectiva histórica, o conceito de imunidade inicialmente se aplicou ao âmbito médico e jurídico. No primeiro caso, ela significou uma forma de isenção ou proteção em relação a uma doença infecciosa. No segundo, ele consistiu em certa salvaguarda em relação a uma lei comum. Segundo Esposito, o dispositivo imunitário progressivamente se estendeu a todos os setores da vida e se tornou o "ponto de coágulo, real e simbólico, da experiência contemporânea. A exigência de preservação da vida, no final da era moderna, representou o eixo em torno do qual se desenvolveram a prática efetiva e o imaginário da população (ESPOSITO, 2017, p. 140).

O protótipo do paradigma imunitário foi desenvolvido por Hobbes, pois ele colocou no centro da sua perspectiva o problema da conservação da vida e a condicionou à subordinação a um poder coativo exterior. A potência da contradição, implícita na lógica da imunização, avançou com Hegel, que considerou o negativo como o próprio motor do positivo. Foi com Nietzsche, porém, que a categoria da imunização foi completamente elaborada. Ele assumiu a alma como a forma imunitária que protege e simultaneamente aprisiona o corpo. Nietzsche interpretou toda a civilização em termos de autopreservação imunitária. Os dispositivos do saber e do poder assumiram uma função de contenção protetora em relação a uma potência vital voltada à expansão ilimitada (ESPOSITO, 2010, p. 74-76).

Nesse contexto, há uma articulação interna entre as modalidades positiva e negativa, de conservação e destruição da vida. Isso diferencia o paradigma imunitário do biopolítico, em que aquelas modalidades não têm pontos de contato: ou o poder nega a vida ou a protege (ESPOSITO, 2010, p. 74).

Ao contrário do que ocorre com o conceito de biopolítica - que decorre do encontro, em certo momento, entre os seus elementos componentes -, no paradigma imunitário não há um poder externo à vida e a vida nunca ocorre fora das relações de poder. A política é, nessas condições, apenas o instrumento de conservação da vida (ESPOSITO, 2010, p. 74). Nas palavras de Esposito (2010, p. 74-75): 
Isto significa que a negação não é forma da sujeição violenta que de fora o poder impõe à vida, mas o modo intrinsicamente antinômico em que a vida se conserva através do poder. Desse ponto de vista pode bem dizer-se que a imunização é uma proteção negativa da vida. Ela salva, assegura, conserva o organismo, individual ou coletivo, a que é inerente - mas não de uma maneira direta, imediata, frontal; submetendo-o, pelo contrário, a uma condição que ao mesmo tempo lhe nega, ou reduz, a força expansiva. Como a prática médica da vacinação em relação a o corpo individual, também a imunização do corpo político funciona introduzindo no seu interior um fragmento da mesma substância patogênica da qual o quer proteger e que, assim, bloqueia e contraria o seu desenvolvimento natural.

\section{MUNUS POSITIVO E NEGATIVO: A IMPLICAÇÃO NEGATIVA ENTRE COMUNIDADE E IMUNIDADE}

No debate acerca da imunidade, Esposito (2010, p. 80) introduziu o conceito de comunidade, relido à luz do seu significado originário e com a sua específica caracterização moderna.

O filósofo italiano se contrapõe ao neocomunitarismo americano e à sociologia organicista alemã, que associam a ideia de comunidade à de pertencimento, identidade e propriedade, como aquilo que identifica alguém com o próprio grupo étnico, a própria terra, a própria língua. É que "comum” é o contrário de próprio: é o que não é apropriável por parte de alguém, que é de todos ou pelo menos de muitos, aquilo que remete ao outro (ESPOSITO, 2017, p. 128).

Mas, sobretudo, a comunidade, na sua origem latina, tem provavelmente o sentido da associação entre cum e munus. Assim, os membros da comunidade são tais porque ligados entre si por um munus: uma tarefa, um dever, uma lei, uma obrigação, um dom a ser doado (ESPOSITO, 2017, p. 69). Essa lei "os leva a sair de si para dirigir-se ao outro e quase a expropriar-se em seu favor" (ESPOSITO, 2017, p. 129).

Nesse sentido, o primeiro conteúdo da lei da comunidade é que ela é necessária. Dessa forma, Esposito afirma que "a comunidade e a lei são um todo no sentido de que a lei comum não prescreve senão a exigência da comunidade mesma". A comunidade é o pressuposto transcendental da existência dos homens, pois desde sempre eles existiram em comum (ESPOSITO, 2017, p. 69).

Assim, a lei da comunidade pode ser compreendida como a necessidade de manutenção daquela condição originária e não subversão no seu oposto. Mas o risco está sempre presente e, desse ponto de vista, é possível afirmar que a comunidade é irrealizável. Ela é, simultaneamente, necessária e impossível (ESPOSITO, 2017, p. 70). 
Esposito afirma que a comunidade é "aquilo que nos determina no distanciamento ou diferença de nós mesmos", "na ruptura de nossa subjetividade" (ESPOSITO, 2010, p. 70) ou “aquela relação que, vinculando os seus membros a um objetivo de doação recíproca, põe em perigo a identidade individual” (ESPOSITO, 2010, p. 80).

A comunidade é, assim, sentida como um risco para a identidade individual do sujeito. Por isso a modernidade desencadeia um processo de imunização, que reconstitui aquela identidade e protege o indivíduo daquilo que difere de si. A imunização é, portanto, a interiorização preventiva e neutralizante do externo (ESPOSITO, 2017, p. 129).

Na sua raiz etimológica, a imunidade também deriva de munus, mas com um sentido negativo: ela é uma forma negativa ou privativa da comunidade. Ela é a condição de dispensa do munus e de defesa em face dos seus esforços expropriatórios. Dispensatio é "aquilo que alivia do pensum de uma obrigação gravosa, assim como a exoneração liberta daquele onus a que é recondutível desde a origem a semântica do munus recíproco" (ESPOSITO, 2010, p. 80). Portanto, imune é aquele que está isento ou exonerado do munus e que pode, por essa razão, conservar íntegra a substância de sujeito proprietário de si (ESPOSITO, 2017, p. 117).

Assim, o significado mais incisivo da imunidade é o reverso lógico da comunidade: imune é o "não ser" ou "não ter" nada em comum. Essa implicação negativa, porém, indica que a imunização pressupõe aquilo que ela nega (ESPOSITO, 2010, p. 81). Para Esposito (2010, p. 82), a comunidade constitui ao mesmo tempo o objeto e o motor da imunidade:

\begin{abstract}
Aquilo que é imunizado, em suma, é a própria comunidade, de uma forma que conjuntamente a conserva e a nega - ou melhor, a conserva através da negação do seu originário horizonte de sentido. Desse ponto de vista poderia chegar-se a dizer que a imunização, mais do que um aparelho de defesa sobreposto à comunidade, é uma sua engrenagem interna. A prega que de algum modo a separa de si própria pondo-a ao abrigo de um excesso não sustentável. A margem diferencial que impede a comunidade coincidir consigo própria assumindo até ao fundo a intensidade semântica do próprio conceito. Para sobreviver, a comunidade, qualquer comunidade, vê-se obrigada a interiorizar a modalidade negativa do seu oposto; mesmo se tal oposto permanece um modo de ser, justamente privador e contrariante, da própria comunidade.
\end{abstract}

\title{
7 A EXIGÊNCIA DE AUTOCONSERVAÇÃO COMO CAUSA DA "INVENÇÃO” DA MODERNIDADE
}

Para Esposito (2010, p. 80-81), a imunidade, enquanto forma privativa da comunidade ou o seu reverso lógico, está estruturalmente conectada à modernidade. Isso não significa que a época moderna possa ser interpretada apenas por meio do paradigma imunitário ou que antes dela a questão da imunidade nunca tenha se colocado. A exigência de autoconservação se estende a toda história da civilização, pois nenhuma sociedade poderia 
existir sem um aparelho defensivo que a protegesse. Esposito (2010, p. 85-86) sustenta que na modernidade o que se altera é a consciência dessa necessidade autoconservadora. Indo mais além, o filósofo italiano chega a afirmar que a exigência de preservação da vida pode ter sido a causa da "invenção" da modernidade (2010, p. 86):

\begin{abstract}
Isto significa que todas as civilizações, passadas e presentes, colocaram, e de alguma maneira resolveram, a exigência da sua própria imunização, mas que apenas a civilização moderna foi por ela constituída na sua mais íntima essência. Poder-se-ia até dizer que não foi a modernidade a pôr a questão da autoconservação da vida, mas sim esta a fazer nascer, e assim a "inventar", a modernidade, como aparelho histórico-categorial capaz de a resolver.
\end{abstract}

Para ele, a imunidade insere a biopolítica em um aspecto temporal historicamente determinado. Sem a imunidade se deveria falar de biopolítica desde o mundo antigo, quando o poder já penetrava na vida biológica: é o caso, por exemplo, dos patrões em relação aos escravos, dos vencedores da guerra em relação aos prisioneiros, do pater familias romano em relação aos seus filhos, ou ainda da política agrária egípcia e da política sanitária de Roma. $\mathrm{O}$ que diferencia esses casos da biopolítica moderna é justamente a questão imunitária (ESPOSITO, 2010, p. 83).

Esposito cita o exemplo de Platão para demonstrar que aquela diferenciação também ocorre no plano conceitual. O grande filósofo antigo parece orientado no sentido biopolítico, pois considera aconselháveis, por exemplo, a aplicação dos métodos de criação para cães para a prole dos cidadãos e as práticas eugênicas para as crianças frágeis e os não adaptados à vida pública. Porém a filosofia platônica não tem um sentido imunitário - de conservação do indivíduo - mas comunitário, voltado ao bem da coletividade. É essa perspectiva "comum" que a cultura pré-moderna em geral conserva e que está aquém de um horizonte completamente biopolítico (2010, p. 83-85).

\title{
8 SOBERANIA, LIBERDADE, PROPRIEDADE: AS CATEGORIAS IMUNITÁRIAS
}

No novo regime biopolítico, caracterizado pelo fenômeno imunitário e estruturalmente conectado à modernidade, a categoria da soberania é a primeira e mais influente figura imunitária. A soberania não está nem antes nem depois da biopolítica, mas atravessa todo o seu horizonte e oferece a mais vigorosa resposta ao problema moderno da autoconservação da vida (ESPOSITO, 2010, p. 89).

Esposito associa o munus com o estado de conflito generalizado teorizado por Thomas Hobbes. A instituição do poder soberano, nesse contexto, objetiva imunizar a 
comunidade do excesso comunitário que a ameaça, ou seja, do desejo dos sujeitos em adquirir bens dos outros, que leva à violência e a efeitos dissolutivos (CAMPBELL, 2017, p. 21).

À política, assim, se confia a tarefa de preservação da vida, porém por meio de um dispositivo antinômico que passa pela ativação do seu contrário. O sistema imunitário natural, que todo organismo possui e o defende de agentes exteriores, é, em face da sua ineficiência, substituído por uma imunidade artificial. A soberania, portanto, representa um segundo dispositivo imunitário, ou mesmo meta-imunitário, destinado a proteger a vida de uma proteção ineficaz e até perigosa (ESPOSITO, 2010, p. 92).

Segundo Esposito (2010, p. 92), é constitutivamente aporética a relação que liga a soberania aos sujeitos a que ela se dirige. O termo é tomado no seu duplo significado: eles são os seus sujeitos, pois a instituíram de forma voluntária por meio de um contrato livre. Ao mesmo tempo, eles lhe estão sujeitos, porque não lhe podem oferecer resistência, o que significaria resistir a si próprios. Eles lhe estão sujeitos precisamente porque são sujeitos dela.

Nesse contexto, o poder soberano e os direitos individuais são o reverso complementar um do outro (2010, p. 93):

[...] só indivíduos iguais entre si podem instituir um soberano capaz de os
representar legitimamente. Ao mesmo tempo, só um soberano absoluto pode libertar
os indivíduos da sujeição a outros poderes despóticos. Como foi esclarecido pela
historiografia mais aguda, muito ao contrário de se excluírem ou se contraporem,
absolutismo e individualismo implicam-se numa relação recondutível ao mesmo
processo genético. Através do absolutismo os indivíduos afirmam-se e negam-se ao
mesmo tempo: pressupondo a sua pressuposição, destituem-se enquanto sujeitos
instituintes a partir do momento em que o resultado dessa instituição não é mais do
que aquilo que por sua vez os institui.

A individualização artificial constituída pelo dispositivo soberano elimina a comunidade e o perigo que ela oferece à vida de todos. Os homens são transformados em indivíduos igualmente absolutos em virtude da supressão do munus que os mantinha unidos. A soberania é, nessa perspectiva, "o não ser em comum dos indivíduos" ou "a forma política da sua dessocialização" (ESPOSITO, 2010, p. 94).

A mesma dialética que simultaneamente une e separa os indivíduos e a soberania invade todas as categorias político-jurídicas da modernidade, em decorrência do fenômeno imunitário. É o caso, por exemplo, da categoria da propriedade. Para Esposito (2010, p. 9698), a inerência da propriedade ao processo de imunização é, por dois motivos, ainda mais pronunciada do que aquela relativa ao conceito de soberania:

Para começar, pela antítese originária que contrapõe "comum" a próprio; sendo por definição "não comum", o próprio é, enquanto tal, sempre imune. Mas também porque a noção de propriedade indica uma intensificação qualitativa de toda a lógica imunitária. Enquanto, de fato, como acaba de se ver, a imunização soberana se verifica transcendente em relação àqueles pelos quais, no entanto, é dada à luz, a 
proprietária mantém-se aderida a eles. Mais: interior às fronteiras do seu próprio corpo. Trata-se de um processo conjunto de imanentização e de especialização: é como se o dispositivo protetor concentrado na figura unitária da soberania se multiplicasse por todos os indivíduos singulares, instalando-se nos seus organismos biológicos.

Segundo a teorização de John Locke, a coisa depende do sujeito que a possui ao ponto de constituir o próprio corpo dele, e o sujeito, por sua vez, se constitui proprietário apenas da coisa que lhe pertence. Ele também é, portanto, dependente dela. Sem um o outro não existe. Quando ocorre o rompimento do nexo estabelecido por Locke entre propriedade e trabalho, que encaixava o "próprio" nas fronteiras do corpo, há a desmaterialização da propriedade. Será considerado próprio apenas aquilo que pode estar longe do corpo daquele que o possui juridicamente (posse jurídica) (ESPOSITO, 2010, p. 101-104).

Essa distância entre o proprietário e a coisa evidencia a contradição implícita na lógica proprietária. O indivíduo proprietário, separado da coisa que não obstante possui de modo inalienável, fica exposto a uma ameaça de esvaziamento ainda mais grave do que aquela de que tinha procurado se imunizar pela aquisição da propriedade. O procedimento apropriativo, que é representado por John Locke como uma personificação da coisa (integração no corpo proprietário), é interpretado como a reitificação da pessoa (descorporização da substância subjetiva) (ESPOSITO, 2010, p. 104-105).

A lógica da propriedade, assim como ocorre com as demais categorias biopolítica modernas, caracteriza-se por um movimento de autorrefutação. O indivíduo proprietário é expropriado por sua potência apropriativa, da mesma forma que foi destituído do poder soberano que ele mesmo instituiu. Essa lógica interna da imunidade é ainda potencializada por uma terceira categoria da era moderna: a liberdade (ESPOSITO, 2010, p. 104-105).

Segundo Esposito (2010, p. 106), o conceito de liberdade originariamente alude a "uma potência conectiva que cresce e se desenvolve segundo a sua lei interna, a uma expansão, a um desdobramento, que junta os seus membros numa dimensão compartilhada". A sua raiz etimológica, assim, está relacionada ao crescimento comum, ao amor, ao afeto, à amizade, à comunidade. Nesse sentido original ela é uma potência agregadora, acomunante, de pertencimento a uma raiz comum que se desenvolve segundo a sua lei interna. É a liberdade $n a$ relação e como relação; com um sentido afirmativo, que remete ao crescimento em comum e consiste justamente no contrário da autonomia e da autossuficiência do indivíduo (ESPOSITO, 2017, p. 132).

$\mathrm{Na}$ sua formulação moderna o conceito sofre uma reconversão negativa, semelhante à operação de neutralização por que passa o de comunidade. A liberdade é entendida não mais 
como um modo de ser, mas como um direito a ter qualquer coisa de seu, o pleno domínio sobre si próprio em relação aos outros. Trata-se de uma acepção negativa que a caracteriza de forma progressivamente exclusiva. A conjugação desse processo entrópico com as estratégias autoconservadoras da sociedade moderna faz com que a antiga liberdade comum se transforme no seu oposto imune (ESPOSITO, 2017, p. 129-130).

A virada do conceito de liberdade na direção imunitária remonta à época medieval, quando ela assume o caráter de direito particular ou conjunto de privilégios e isenções que dispensam certas classes de uma obrigação comum com os outros (ESPOSITO, 2017, p. 133).

A partir de então ela é sempre concebida como uma faculdade do indivíduo que a detém. Com Hobbes ela se relaciona à proteção da vida e, com Locke, à proteção da propriedade privada. Em ambos os casos, ela se contrapõe claramente à dimensão política. A partir dos séculos XVII e XVIII, a liberdade se relaciona à segurança, pois livre é o indivíduo que está seguro. A última passagem da "deriva anticomunitária" ocorre com a identificação da liberdade com a propriedade: livre é o sujeito proprietário daquilo que lhe pertence (ESPOSITO, 2017, p. 133).

Esposito (2017, p. 135-136) afirma que devemos reconduzir a liberdade ao seu significado primário. Ela, nesse sentido, é a dimensão singular da comunidade. É a comunidade estendida nas infinitas singularidades que constituem a pluralidade. É o que, da comunidade, resiste ao processo imunizatório.

\section{OS MUROS ERGUIDOS PELO EXCESSO DE IMUNIZAÇÃO E O RESGATE DA DIMENSÃO COMUNITÁRIA}

Conforme foi exposto no tópico anterior, a categoria da imunidade permite compreender as categorias político-jurídicos da modernidade, como a soberania, a propriedade e a liberdade. Segundo Esposito (2017, p. 117), a imunidade, no seu contraste com a comunidade, é o mais frutífero instrumento de interpretação dos sistemas políticos modernos e confere densidade problemática também à análise da democracia. A escolha etimológico-paradigmática de co-implicação dos conceitos de imunidade e comunidade, além de eliminar a possibilidade de que eles possam ser dispostos ao longo de uma linha de sucessão histórica, abre um amplo horizonte de visibilidade sobre a democracia, que é compreendida principalmente a partir de uma perspectiva sócio-antropológica.

Nesse sentido, é possível afirmar que na modernidade a democracia progressivamente introduz uma exigência imunitária e, dessa forma, se opõe à comunidade (ESPOSITO, 2017, p. 117 e 119): 
[...] a exoneração da contingência ambiental, assegurada pelas instituições, coincide, para o indivíduo democrático, com uma tomada de distância do mundo em que ele está radicado, e por isso mesmo, com uma suspensão daquele munus comum que o obriga em relação aos outros. Desse modo ele é levado a fechar a sua abertura original e a circunscrever-se à esfera do próprio interior. O que mais é a imunização, se não uma forma de progressiva interiorização da exterioridade? Se a comunidade é o nosso "fora", o fora-de-nós, a imunização é o que nos redireciona ao interior de nós mesmos, rompendo todo contato com o exterior.

Nesse contexto, Esposito (2017, p. 121-122) afirma que o pensamento sobre a comunidade está exposto ao duplo risco do esquecimento e da deformação. O primeiro deles se relaciona à queda do comunismo, que ocasionou um vazio de ideias no qual a questão comunitária foi desacreditada em virtude dos erros e horrores dos regimes que sucumbiram. $\mathrm{O}$ risco mais grave, porém, é o da perversão da comunidade no seu oposto: aquilo "que eleva muros em vez de abatê-los". Isso ocorre não apenas na periferia, mas também no centro do mundo, com o que Esposito chama de "pequenas pátrias fechadas e muradas diante de seus exteriores, contrapostas e hostis a tudo que não lhes pertence”.

Se levada ao extremo, a ideia de imunidade, que é necessária para proteger a nossa vida, acaba por negá-la e destruí-la. O excesso de imunização, segundo Esposito (2017, p. 143), "obriga a uma espécie de jaula, ou armadura, na qual se perde não somente a nossa liberdade, mas o próprio sentido da nossa existência individual e coletiva”. É como se os procedimentos imunitários estivessem progressivamente aumentando a dose de veneno do remédio.

Esposito afirma que se está alcançando um limite no qual a lógica imunitária arrisca fugir do controle. Ele faz uma analogia com as doenças autoimunes, nas quais o sistema imunitário é tão potencializado a ponto de destruir o próprio mecanismo que deveria defender (2017, p. 144).

O filósofo italiano cita os eventos de 11 de setembro de 2011, relacionando-os a duas obsessões imunitárias opostas: de um lado, o fundamentalismo islâmico destinado a proteger da secularização ocidental a sua suposta pureza religiosa, étnica, cultural e, de outro, o Ocidente dedicado a não compartilhar os seus bens excedentes com o resto do mundo. $\mathrm{O}$ excesso de defesa em relação a corpos estranhos produziu efeitos letais no próprio organismo (ESPOSITO, 2017, p. 144).

O monoteísmo político, para Esposito, corresponde à versão mais violenta da imunização: “o fechamento das fronteiras que não toleram nada do próprio exterior, que excluem a própria ideia de um exterior, que não admitem nenhuma estraneidade que possa ameaçar a lógica do "Um-tudo"” (ESPOSITO, 2017, p. 145). 
Nesse contexto, o fenômeno da globalização, que expressa o definitivo fechamento do sistema imunitário sobre si mesmo, pode também pode ser compreendido como a recondução do mundo à sua fenomenicidade: o mundo que é apenas mundo, sem pressupostos, origens ou fins transcendentais. Nessa perspectiva, Esposito afirma que é possível pensar em uma democracia igualmente planetária, uma comunidade mundial. No seu ápice a imunização poderia imunizar a si mesma, resgatando a comunidade. Um mundo sem exterior (totalmente imunizado) é também um mundo sem interior (ESPOSITO, 2017, p. 124).

O processo de imunização, assim, não deve necessariamente degenerar. Esposito desenvolve um modelo afirmativo de biopolítica (CAMPBELL, 2017, p. 27) e propõe que a solução para o excesso de imunização passe pela construção de uma relação inédita entre singular e mundial (ESPOSITO, 2017, p. 146-147):

O mundo - já irreversivelmente unido - deve ser não somente pensado, mas
"praticado", como unidade de diferenças, como sistema de distinções, em que
distinções e diferenças não sejam pontos de resistência ou resíduos em relação aos
processos de globalização, mas a sua própria forma. Naturalmente sei bem que
transformar essa fórmula filosófica em prática real, em lógica política, é empresa
nada fácil. E, no entanto, é preciso encontrar o modo, as formas, a linguagem
conceitual para converter a caracterização imunitária que assumiram todos os
fundamentalismos políticos em uma lógica singular e plural, em que as diferenças se
tornem precisamente o que mantém unido o mundo.

\section{CONSIDERAÇÕES FINAIS}

Foucault demonstrou que a teoria da soberania é insuficiente para explicar a forma pela qual o poder se exerce modernamente. Ele identificou a existência do poder normalizador, que se utiliza de tecnologias disciplinares em face dos indivíduos e de dispositivos de segurança sobre a população para adequá-los a uma norma. Esta, por sua vez, não se confunde com a clássica fonte do direito materializada na lei. Tanto o Estado como as instituições privadas veiculam a nova forma de poder que toma conta da vida.

Tendo como base os estudos de Foucault, Roberto Esposito contribuiu de forma importante ao avanço dos estudos biopolíticos. No paradigma por ele desenvolvido, o conceito de imunidade liga a vida e a política, os dois polos constitutivos da biopolíca, em um único e indivisível conjunto. Ela não apenas promove essa ligação, mas se constitui no poder de conservação da vida.

A imunidade é por ele compreendida a partir da análise do seu "reverso oposto": a comunidade, cujo conceito é relido a partir do seu significado originário e com a sua específica conotação moderna. Esposito desenvolve a ideia de que a comunidade vincula os 
seus membros por meio de um objetivo de doação recíproca, o que põe em risco a identidade individual e desencadeia o processo de imunização. Ao liberar o sujeito do munus que é inerente à comunidade, a imunidade se constitui em uma forma negativa ou privativa de comunidade. É interessante notar a implicação entre os conceitos: a imunização pressupõe aquilo que ela nega, enquanto a comunidade é simultaneamente o objeto e o motor da imunidade.

Esposito situa o paradigma imunitário na modernidade, quando surge a consciência da necessidade de autoconservação da vida. O filósofo também demonstra como o fenômeno imunitário invade as categorias político-jurídicas da soberania, propriedade e liberdade.

O risco do excesso de imunização não passou desapercebido. Esposito sustenta que a ideia de imunidade, se levada ao extremo, pode negar e destruir a própria vida, que ela buscava proteger. Nesse contexto, ele defende que seja construída uma relação inédita entre singular e mundial para solucionar o problema decorrente daquele excesso. As diferenças devem se tornar o que mantém unido o mundo.

Conforme bem captou Timothy Campbel (2017, p. 66), Esposito se propõe a “elaborar uma biopolítica afirmativa que, através de uma compreensão cada vez mais límpida da dialética entre comunidade e imunidade, contraste todo critério excludente de qualificação da vida".

\section{REFERÊNCIAS BIBLIOGRÁFICAS}

CAMPBEL, Timothy. Política, Imunidade, Vida: o pensamento de Roberto Esposito no debate contemporâneo. In: ESPOSITO, Roberto. Termos da política: comunidade, imunidade, biopolítica. Curitiba: Editora UFPR, 2017. p. 13-66.

ESPOSITO, Roberto. A Lei da Comunidade. In: ESPOSITO, Roberto. Termos da política: comunidade, imunidade, biopolítica. Curitiba: Editora UFPR, 2017. p. 69-82.

ESPOSITO, Roberto. Bios: biopolítica e filosofia. Lisboa: Edições 70, 2010.

ESPOSITO, Roberto. Democracia Imunitária. In: ESPOSITO, Roberto.
Termos da política: comunidade, imunidade, biopolítica. Curitiba: Editora UFPR, 2017. p. 115-125.

ESPOSITO, Roberto. Imunização e Violência. In: ESPOSITO, Roberto. Termos da política: comunidade, imunidade, biopolítica. Curitiba: Editora UFPR, 2017. p. 139-148.

ESPOSITO, Roberto. Liberdade e imunidade. In: ESPOSITO, Roberto. Termos da política: comunidade, imunidade, biopolítica. Curitiba: Editora UFPR, 2017. p. 127-137. 
FONSECA, Ricardo Marcelo. Introdução Teórica à História do Direito. Curitiba: Juruá, 2012.

FONSECA, Ricardo Marcelo. Modernidade e contrato de trabalho: do sujeito de direito à sujeição jurídica. São Paulo: LTr, 2002.

FONSECA, Ricardo Marcelo. O poder entre o direito e a "norma": Foucault e Deleuze na Teoria do Estado. In: FONSECA, Ricardo Marcelo (Org.). Repensando a teoria do Estado. Belo Horizonte: Forum, 2004. p. 259-281.
FOUCAULT, Michel. Em Defesa da Sociedade. Curso no Collège de France (1975-1976). Tradução de Maria Ermantina Galvão. São Paulo: Martins Fontes, 2005.

FOUCAULT, Michel. Segurança, Território, População. Curso dado no Collège de France (1977-1978). Tradução de Eduardo Brandão. São Paulo: Martins Fontes, 2008.

\section{BIOPOLITICS AND ROBERTO ESPOSITO'S IMMUNITY PARADIGM}

Ana Paula Sabetzki Boeing

How to cite this article: SABETZKI BOEING, Ana Paula. Biopolítica e o paradigma imunitário de Roberto Esposito. Revista de Ciências do Estado. Belo Horizonte: v. 5, n. 1, e14832. ISSN: 2525-8036.

Abstract: the aim of this paper is to analyze the immunity paradigm developed by Roberto Esposito in the field of biopolitics. The research is qualitative and uses Brazilian and foreign legal doctrine. The conclusion is that Esposito's notion of immunity is structurally connected with modernity, has a negative implication with community, and a sense of connection between life and power, but can destroy life if carried to the extreme. In addition, immunity influences the traditional legal-political categories of sovereignty, liberty, and property.

Keywords: biopolitics; Roberto Esposito; immunity; community. 